\title{
Barriers to Sustained Return-to-Work Reported by those Returning to Work Post Traumatic Spinal Cord Injury Rehabilitation
}

\author{
Gregory C. Murphy* and Mervyn S. Jackson \\ School of Public Health, La Trobe University, Bundoora, 3083, Australia \\ School of Health Sciences, RMIT University, Bundoora, 3083, Australia
}

\begin{abstract}
Aim: The first aim of this cross-sectional survey was to assess the reasons given by people with traumatic spinal cord injury (tSCI) for leaving a job that they had secured after sustaining injury. The second aim was to examine the extent to which these reasons were compatible with a previously-developed framework for understanding organizational behaviors such as leaving a position of employment.

Method: Thirty tSCI patients who left a position of employment which had been secured following the injury were interviewed, and asked to report the factors associated with their withdrawal from that position of employment.

Results: A large number of factors were reportedly involved in the withdrawals. These factors mirrored were those which have been identified as influencing organizational behavior among the general workforce (characteristics of the individual, of the job, and of the wider environment). The ratio of factors involved was, respectively, 8:8:1. Within the environmental factors, micro-level factors were more prevalent than macro-level factors (in the ratio of 2:1).

Conclusions: As many of the individual, job, and health-related reasons are essentially immutable, the environmental factors offer more promise for the development of preventive interventions to minimize unnecessary job loss. Prominent among these environmental factors targeted in interventions would be the workplace-related factor of social support.
\end{abstract}

Keywords: Employment, social support, traumatic spinal cord injury.

\section{INTRODUCTION}

Little is known about what workers consider to be the most influential factors related to employment maintenance following return to work from injury [1]. Amongst the traumatic spinal-cord-injury population, the retrospective survey of Young and Murphy [2] produced results indicating that (alongside extraneous factors such as management decisions to retrench the returning employee), person-job mismatches were the most commonly reported reasons for leaving a job gained post-injury, mentioned by $34 \%$ of the sample of 190 participants.

Within the general population of workers' compensation claimants as well as within the smaller population of those suffering traumatic spinal cord injury, high rates of durable (i.e. sustained) returns to work have been difficult to achieve. In Australian jurisdictions a durable return to work situation is defined as one in which an injured worker, having returned to work post injury, is still at work when followed up at 6 months post initial injury. Typically, only $75 \%$ of Australian work-injured employees achieve a durable return to work [3]. From research into vocational achievement following spinal cord injury, both North American and Australian studies indicate that approximately $20 \%$ of the prevalence population of those discharged from hospital with

*Address correspondence to this author at the School of Public Health, La Trobe University, 3083, Australia; Tel: + 613 94791745; Fax: + 6139479 1783; E-mail: G.Murphy@latrobe.edu.au a persisting neurological deficit return to work but withdraw from the labour force subsequently [4]. To date, most vocational rehabilitation research involving this neurotrauma population has focused on the influence of a limited number of demographic and injury factors on post-injury employment but with little attempt to identify the processes or factors involved in either return to, or withdrawal from, work gained post-injury. Thus the wider research program of which this paper is one part, sought to fill this gap by undertaking a comprehensive three-phase research program to identify the multifarious factors that lead to post-injury job withdrawal among those living with traumatic SCI and also to identify and evaluate targeted interventions designed to minimize the impact of those job-withdrawal factors that were preventable.

\section{THE PRESENT STUDY}

The overall aim of the parent research program was to enhance employment retention following return to work post traumatic spinal cord injury (tSCI). To achieve this aim, a three-phase research project was undertaken. The specific aims of each phase were to:

1. Identify the reported factors that led to post-injury job withdrawal among those living with tSCI (Phase 1), and to assess the extent to which these factors fell within previously established categories of variables influencing employees' organizational behaviour. 
2. Identify potential interventions designed to minimize the impact of the reported job withdrawal factors (Phase 2).

3. Evaluate the perceived benefits and drawbacks of the proposed interventions (Phase 3 ).

This paper reports on results from Phase 1 of the research program.

\section{METHOD}

\section{Participants}

The sample comprised 30 traumatic spinal cord injury survivors. Although the original sample pool was 36, three participants did not meet study criteria and a group of further three participants did not reply to e-mail requests for the follow-up telephone interview. The final sample was broadly representative of the Australian spinal cord injury in terms of gender and injury severity (see Cripps [5]). The majority of the sample was male $(80 \%)$, received some form of compensation $(60 \%)$ and lived in suburban areas $(50 \%)$. Quadriplegias were slightly more prevalent than paraplegias (58\% vs 42\%). Half of the sample was injured as young adults (20-29 years of age) while $83 \%$ of participants had been living with SCI for 10 or more years at the time of interview.

\section{Study Design and Procedure}

Purposive sampling was used to recruit participants. The Australian Quadriplegia Association (AQA) Victoria emailed its members with a brief overview of the study and its aims. Interested volunteers were invited to contact the principal researcher at LaTrobe University for further information. All volunteers then completed an online prescreening survey, accessed through the AQA website, to gather general demographic, injury and employment data. Eligibility to participate in the survey was also stablished (i.e., participants to be restricted to those who had withdrawn from post-injury employment). Participants were then asked if they would be interested in completing an in-depth interview (either by telephone or in-person) and to supply contact details if they consented. The LaTrobe University researchers then contacted participants and outlined the study, its aims, and risks. If participants still wished to be interviewed, an appointment was made. Participants were offered the option of being interviewed either by telephone or in-person (all participants opted for telephone interviews). Participants could consent, decline or withdraw at any time without repercussions of any kind. Participation was voluntary, confidential and independent of AQA membership and accessible to its services. All participants could elect to go into a draw for one of three nano ipods, to be drawn at the completion of the study. The study was approved by the relevant LaTrobe University Ethics Committee.

\section{RESULTS}

Content analysis of participants' interview responses indicated that reasons could be categorized into three factors: individual-level factors; job-related factors; and social and economic factors.

\section{Individual-Level Factors}

As can be seen from Table 1, individual level factors were cited 199 times. Within the individual-level factors group, the most frequently cited reasons fell into the following five broad categories (in descending order of frequency): (i) Injury and disability factors (61, 30.6\%); (ii) SCI-related issues $(57,28.6 \%)$; (iii) General health issues (36, 18.1\%); (iv) Psychological factors (27, 13.6\%); (v) Knowledge, skills and abilities (18, 9.1\%).

\section{Job-Related Factors}

As can be seen from Table 2, job-related factors were cited 202 times. Within the job-related factors group, the most frequently cited reasons fell into the following five broad categories (in descending order of frequency): (i) Job design (57, 28.2\%); (ii) Psychosocial climate (52, 25.7\%); (iii) Ergonomic factors $(45,22.3 \%)$; (iv) Human resources (28, 13.9\%); (v) Work cycles $(20,9.9 \%)$.

\section{Social and Economic Factors}

As can be seen from Table 3, social and economic factors were cited 75 times. Social and economic factors were divided into two levels: macro-level and micro-level. Microlevel factors included family priorities, finances and relationships while macro-level factors included negative societal attitudes, government policy and the job market. As job withdrawal stimuli, micro-level economic and social factors were cited twice as frequently as were macro-level factors (50 times versus 25 times).

\section{DISCUSSION}

The twin aims of this study were to investigate (1) the reported reasons of interviewees for their leaving a job that they had returned to, or gained, post the suffering of a traumatic spinal cord injury (tSCI); and (2) the extent to which these reasons were compatible with a previouslydeveloped framework for understanding organizational behavior, as proposed originally by Porter and Miles [6], and later extended to cover tSCI employees by Murphy [7].

The study participants reported a wide range of factors across all of the organizational behavior (OB) sources of influence as proposed by Porter and Miles, and Murphy: (i) characteristics of the individual; (ii) characteristics of the job; (iii) characteristics of the work environment; and (iv) characteristics of the non-work environment. The large number of reasons given was consistent with results from general social psychology studies of the relationship between people's planned and their actual behavior (see Ajzen [8]). General social psychology models for predicting an individual's behavior hold that behavior is "overdetermined" and that, if one takes a behavior of interest such as a particular job withdrawal, many factors combine to produce that withdrawal. Equally, if just one of those factors was to change, the withdrawal may well not have occurred.

Major bodies of psychological theory (see for example attribution theory [9]) and Vroom's [10] attribution-theory explanations (see page 149) for the potentially invalid results produced when employees were surveyed about such matters as "determinants" of their own behavior, would suggest that 
Table 1. Individual-Level Factors that Influenced Job Withdrawal

\begin{tabular}{|c|c|c|}
\hline Factors & Frequency & Percent* \\
\hline \multicolumn{3}{|l|}{ Injury and Disability Factors } \\
\hline Wheelchair bound & 16 & 53.3 \\
\hline Travel distance & 12 & 40.0 \\
\hline Others' expectations & 12 & 40.0 \\
\hline Inadequate functional ability & 9 & 30.0 \\
\hline Afraid to let others down & 5 & 16.7 \\
\hline Public transport & 4 & 13.3 \\
\hline Risk of work injury & 3 & 10.0 \\
\hline \multicolumn{3}{|l|}{ SCI-Related Issues } \\
\hline Bowel / bladder management & 13 & 43.3 \\
\hline Pain management & 12 & 40.0 \\
\hline Level of disability & 12 & 40.0 \\
\hline Pressure sore management & 4 & 13.3 \\
\hline Urinary tract infections & 4 & 13.3 \\
\hline Scheduled for re-admission & 4 & 13.3 \\
\hline Other self-care issues & 4 & 13.3 \\
\hline Required excessive sick-leave & 2 & 6.7 \\
\hline Respiratory problems & 2 & \\
\hline \multicolumn{3}{|l|}{ General Health Issues } \\
\hline Prone to fatigue & 11 & 36.7 \\
\hline Medical complications & 10 & 33.3 \\
\hline Sleep problems & 6 & 20.0 \\
\hline Depression & 6 & 20.0 \\
\hline Anxiety & 3 & 10.0 \\
\hline \multicolumn{3}{|l|}{ Psychological Factors } \\
\hline Fearful of re-injury & 5 & 16.7 \\
\hline Self-esteem / confidence issues & 4 & 13.3 \\
\hline Lack of coping skills & 4 & 13.3 \\
\hline Embarrassment & 4 & 13.3 \\
\hline Frustration & 4 & 13.3 \\
\hline Disillusionment & 3 & 10.0 \\
\hline Lack of emotional support & 3 & 10.0 \\
\hline \multicolumn{3}{|l|}{ Knowledge, Skills and Abilities } \\
\hline Required re-training & 8 & 26.7 \\
\hline Inadequate educational level & 6 & 20.0 \\
\hline Lack of relevant skills & 2 & 6.7 \\
\hline Inexperience in new role & 2 & 6.7 \\
\hline GRAND TOTAL & 199 & 100.0 \\
\hline
\end{tabular}

there are questions about the validity of many job-design, and health-related issues, when reported as factors influencing job withdrawal. While many of the reported reasons may well have been accurate, both job-design and employee-health reasons are socially acceptable reasons for quitting a position of employment, and thus this methodological issue needs to be kept in mind when interpreting the results.

The most interesting results from both a vocational rehabilitation and an organizational behavior perspective were those relating to work-environment factors, particularly the attitudes and behavior of co-workers and of immediate supervisors. A lack of workplace social support was clearly the single most frequently reported influencing factor, being mentioned by over half of those interviewed. Environmental influences are important to understand as, in many cases, these are far more malleable than many of the individual health and job characteristics. In Young's [1] prospective study of variables that differentiated between those who maintained employment following their return to work post injury as opposed to those who did not maintain employment, the employee's relationship with his/her supervisor was the sole differentiating predictor variable among a set of fifteen demographic, injury and work-related variables. Consistent with Young's finding that the supervisor was a key environmental factor in facilitating sustained return to work, Lotters and colleagues' study [11] into the reliable attendance of work-injured employees who returned to work found that the quality of the supervisorsubordinate relationship was an independent predictor of continuity of post-return attendance.

Two practical implications flow from the current results. First, educational efforts directed at members of the immediate work group may be useful in preventing some of these withdrawals. Effective supervisor training in this area has been linked with reduced job withdrawals by subordinates (see Shaw [12]) and been evaluated in healtheconomic analyses as providing a high return on investment (see Murphy and Cott [13]). Second, Rehabilitation Counsellors and Case Managers probably need to spend more time assessing the local work environment both prior to, and following, a return to work. The social climate of the workplace may take time to assess reliability, but studies by Disability Management researchers such Amick, Habeck and colleagues [14] have clearly identified workplace policy and practices relating to work injury and return to work as having a reliable, independent effect on occupational rehabilitation outcomes, amongst which durable returns to work are most valued, even if rarely studied to date.

\section{LIMITATIONS}

The small sample size $(n=30)$ is an obvious study limitation, as is the collection of data from one source only (the former employee) with no data provided by other parties, such as workplace colleagues or family members. However, this exploratory research project attempted to provide detail about a rarely-studied phenomenon (nondurable return-to-work situations post $\mathrm{tSCI}$ ), and the sample was broadly representative of the Australian tSCI population. 
Table 2. Job Characteristics that Influenced Job Withdrawal

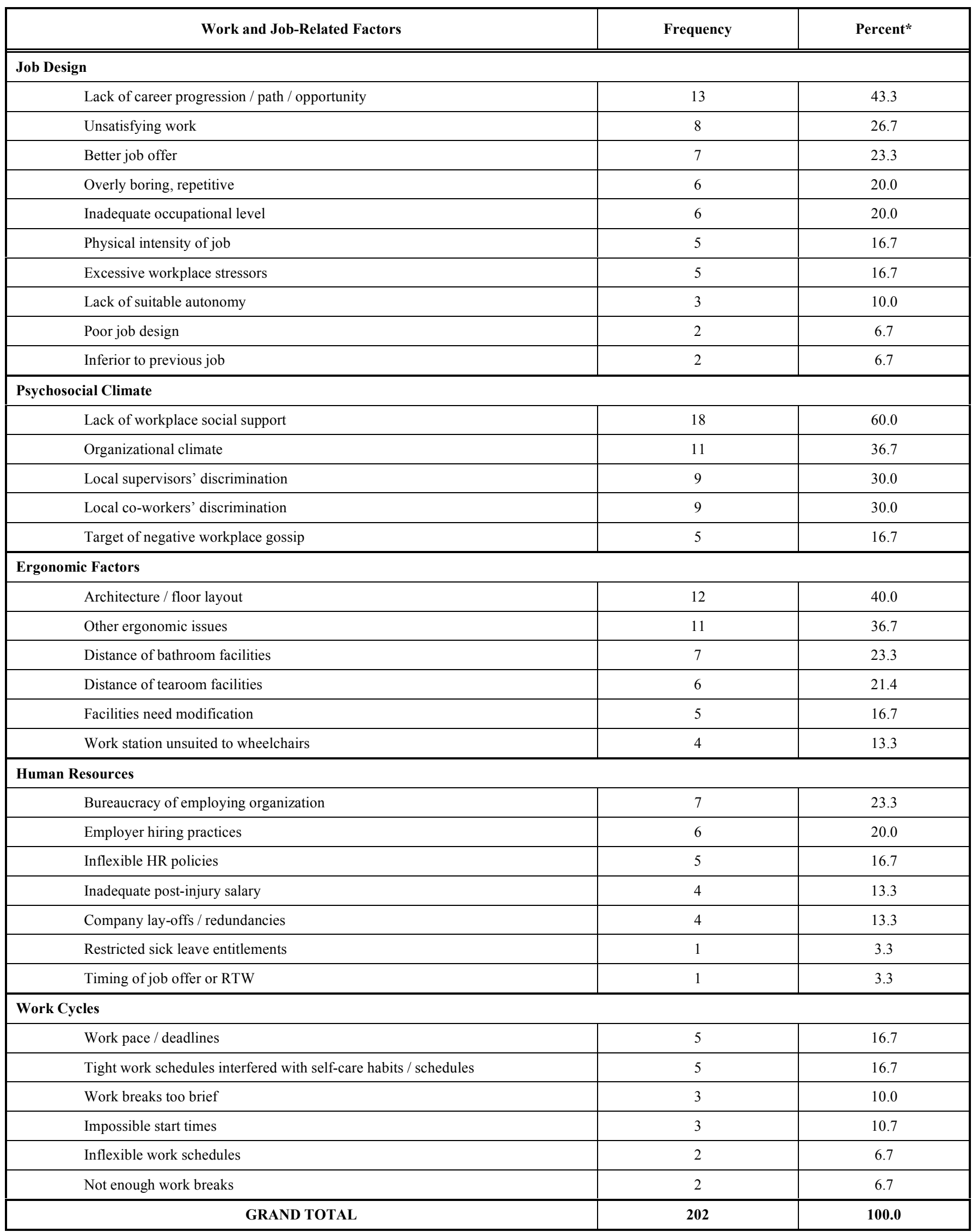


Table 3. Social and Economic Factors that Influenced Job Withdrawal

\begin{tabular}{|c|c|c|}
\hline Factors & Frequency & Percent* \\
\hline \multicolumn{3}{|l|}{ Micro-Level Factors } \\
\hline Finances & 10 & 33.3 \\
\hline Inadequate rehabilitation programs & 10 & 33.3 \\
\hline Lack of home help & 4 & 13.3 \\
\hline High travel costs & 3 & 10.0 \\
\hline Significant reduction or loss of compensation or benefits & 2 & 6.7 \\
\hline \multicolumn{3}{|l|}{ Macro-Level Factors } \\
\hline Unemployment level & 4 & 13.3 \\
\hline Recession & 3 & 10.0 \\
\hline GRAND TOTAL & 75 & 100.0 \\
\hline
\end{tabular}

${ }^{*}$ Calculated as $\%$ of $n=30$ for each option (i.e. as a $\%$ of the total sample).

\section{CONCLUSION}

As many of the individual, job, and health-related reasons are essentially immutable, specially when dealing with the many permanent impairments associated with tSCI, the environmental factors offer more promise for the development of preventive interventions to minimize unnecessary job loss. Based on cost-benefit analysis, and consistent with current findings plus previous results a promising target among these environmental factors appears to be the workplace-related factor of supervisor support.

\section{CONFLICT OF INTEREST}

The authors confirm that this article content has no conflict of interest.

\section{ACKNOWLEDGEMENTS}

This study was supported by a grant from the Transport Accident Commission of Victoria (VNI Collaborative grant DC 19).

\section{REFERENCES}

[1] Young A. Employment maintenance and the factors that impact it after vocational rehabilitation and return to work. Disabil Rehabil 2010; 32: 1621-32.

[2] Young A, Murphy G. Vocationally-oriented rehabilitation service requests: the case of employed persons experiencing a spinal cord injury. Aust J Career Dev 2002; 12: 9-16.
[3] Heads of Workers' Compensation Authorities ANZ. Return to work monitor. Campbell Research and Consulting, Melbourne Australia; 2012

[4] Young A, Murphy G. Employment status after spinal cord injury. Int J Rehabil Res 2009; 32: 1-11.

[5] Cripps R. Spinal cord injury, Australia 2004-2005. Injury Research and Statistics Series Number 29. Adelaide: Australian Institute of Health and Welfare 2006.

[6] Porter L, Miles N. Motivation and management. McGuire J, Ed. Contemporary Management: Issues and viewpoints. Prentice Hall: Englewood Cliffs, N.J. 1974.

[7] Murphy G. Using unpredicted vocational outcomes following traumatic spinal cord injury to identify powerful, novel return-to-work barriers and facilitators. In: Berkovsky T, Ed. Spinal cord injuries: Types, treatment and prognosis. Nova Science: New York 2009; pp. 565-78.

[8] Ajzen I. Attitude, personality and behavior. Open University Press: Milton Keynes, England 1988.

[9] Weiner B. Reflections on the history of attribution theory and research. Social Psych 2008; 38: 151-6.

[10] Vroom, V. Work and motivation. Jossey Bass: San Francisco 1995.

[11] Lotters F, Meeding W-J, Burdorf A. Reduced productivity after sickness absence due to musculoskeletal disarders and its relation to health outcomes. Scand J Work Environ Health 2005; 31: 367-74.

[12] McClellan R, Pransky G, Shaw W. Disability Management training for supervisors: A pilot intervention. J Occup Rehabil 2001; 11: 33-9.

[13] Murphy G, Cott C. Prevention of unnecessary job loss following return to work post traumatic spinal cord injury rehabilitation. Final report on Project DC 19 Victorian Neurotrauma Initiative: Melbourne 2012.

[14] Amick B, Habeck R, Hunt A, et al. Measuring the impact of organizational behavior on workplace disability prevention and management. J Occup Rehabil 2001; 10: 21-38.

(C) Murphy and Jackson; Licensee Bentham Open.

This is an open access article licensed under the terms of the Creative Commons Attribution Non-Commercial License (http: //creativecommons.org/licenses/by$\mathrm{nc} / 3.0 /$ ) which permits unrestricted, non-commercial use, distribution and reproduction in any medium, provided the work is properly cited. 